\title{
Cytoprotective Effects of Punicalagin on Hydrogen-Peroxide-Mediated Oxidative Stress and Mitochondrial Dysfunction in Retinal Pigment Epithelium Cells
}

\author{
Maria Elisabetta Clementi ${ }^{1, *,+}\left(\mathbb{0}\right.$, Giuseppe Maulucci ${ }^{2,3,+} \oplus$, Giada Bianchetti ${ }^{2,3}{ }^{(0)}$, Michela Pizzoferrato ${ }^{3,4}$, \\ Beatrice Sampaolese ${ }^{1}$ (D) and Giuseppe Tringali ${ }^{3,4, *}$ (D) \\ 1 Institute of Chemical Sciences and Technologies "Giulio Natta" (SCITEC)—CNR, L.go F. Vito 1, \\ 00168 Rome, Italy; beatrice.sampaolese@scitec.cnr.it \\ 2 Biophysics Section, Neuroscience Department, Università Cattolica Del Sacro Cuore, Largo F. Vito 1, \\ 00168 Rome, Italy; giuseppe.maulucci@unicatt.it (G.M.); giada.bianchetti@unicatt.it (G.B.) \\ 3 Fondazione Policlinico Universitario A, Gemelli IRCSS, 00168 Rome, Italy; michela.pizzoferrato@gmail.com \\ 4 Pharmacology Section, Department of Health Care Surveillance and Bioethics, Università Cattolica del Sacro \\ Cuore, Largo F. Vito 1, 00168 Rome, Italy \\ * Correspondence: elisabetta.clementi@scitec.cnr.it (M.E.C.); giuseppe.tringali@unicatt.it (G.T.); \\ Tel.: +39-063-015-4215 (M.E.C.); +39-063-015-4367 (G.T.) \\ + Contributed equally to this work.
}

check for updates

Citation: Clementi, M.E.; Maulucci, G.; Bianchetti, G.; Pizzoferrato, M.; Sampaolese, B.; Tringali, G.

Cytoprotective Effects of Punicalagin on Hydrogen-Peroxide-Mediated Oxidative Stress and Mitochondrial Dysfunction in Retinal Pigment Epithelium Cells. Antioxidants 2021, 10, 192. https://doi.org/10.3390/ antiox10020192

Academic Editor: Pamela M. Martin Received: 21 December 2020

Accepted: 23 January 2021

Published: 29 January 2021

Publisher's Note: MDPI stays neutral with regard to jurisdictional claims in published maps and institutional affiliations.

Copyright: (c) 2021 by the authors. Licensee MDPI, Basel, Switzerland. This article is an open access article distributed under the terms and conditions of the Creative Commons Attribution (CC BY) license (https:// creativecommons.org/licenses/by/ $4.0 /)$.

\begin{abstract}
The retinal pigment epithelium (RPE) is a densely pigmented, monostratified epithelium that provides metabolic and functional support to the outer segments of photoreceptors. Endogenous or exogenous oxidative stimuli determine a switch from physiological to pathological conditions, characterized by an increase of intracellular levels of reactive oxygen species (ROS). Accumulating evidence has elucidated that punicalagin (PUN), the major ellagitannin in pomegranate, is a potent antioxidant in several cell types. The present study aimed to investigate the protective effect of PUN on mitochondrial dysfunction associated with hydrogen peroxide $\left(\mathrm{H}_{2} \mathrm{O}_{2}\right)$-induced oxidative stress. For this purpose, we used a human RPE cell line (ARPE-19) exposed to $\mathrm{H}_{2} \mathrm{O}_{2}$ for $24 \mathrm{~h}$. The effects of PUN pre-treatment $(24 \mathrm{~h})$ were examined on cell viability, mitochondrial ROS levels, mitochondrial membrane potential, and respiratory chain complexes, then finally on caspase- 3 enzymatic activity. The results showed that supplementation with PUN: (a) significantly increased cell viability; (b) kept the mitochondrial membrane potential $(\Delta \Psi \mathrm{m})$ at healthy levels and limited ROS production; (c) preserved the activity of respiratory complexes; (d) reduced caspase-3 activity. In conclusion, due to its activity in helping mitochondrial functions, reducing oxidative stress, and subsequent induction of cellular apoptosis, PUN might be considered a useful nutraceutical agent in the treatment of oxidation-associated disorders of RPE.
\end{abstract}

Keywords: punicalagin; ARPE-19 (human-RPE cell line); mitochondrion; oxidative stress

\section{Introduction}

The retinal pigment epithelium (RPE) is a dynamic barrier between the retina and the systemic circulation barrier, which is implicated in many fundamental functions that support photoreceptor health and integrity [1-3]. The RPE maintains retina and choriocapillaris homeostasis, checking the transport of nutrient substances, removing harmful ones, and releasing neurotrophic and growth factors to and from the retina [4,5]. It is, therefore, not surprising that the integrity, dysfunction, and atrophy of the RPE play important roles in the switch between physiology and pathology [6,7].

Chronic dysfunctions of the RPE are associated with various degenerative ocular pathologies, including age-related macular degeneration or Stargardt disease [8,9]. The aging process and oxidative damage to the RPE, which are linked to high reactive oxygen 
species (ROS) levels, have been identified as main factors contributing to these pathologies $[7,10]$. In fact, although the RPE can counteract ROS via different mechanisms, exposure to exogenous stressors may induce an overproduction of ROS and consequently promote an imbalance between production and neutralization, which is the basis of the pathogenesis of degenerative ocular diseases [11-13].

Recent scientific evidence suggests that degenerative retinal diseases have a common root: oxidative-stress-induced mitochondrial dysfunction of the RPE cells [14,15]. Due to this, RPE mitochondria have been suggested as new therapeutic targets for these pathologies [16]. In this regard, pre-clinical and clinical studies have highlighted that an adequate supply of antioxidant substances represents a potential therapy for prophylaxis or in treatment of chronic retinal diseases [17-19]. In particular, nutraceutical antioxidants have been proven effective as both ROS scavengers and inhibitors or inducers of the mitochondrial signaling pathways related to adaptive responses to oxidative stress [20-24].

Punicalagin (2,3-hexahydroxydiphenoyl-gallagyl- $D$-glucose; PUN), a polyphenol extracted from pomegranate (Punica granatum), is a promising multifunctional molecule with anti-inflammatory, antiproliferative, hepatoprotective, and antigenotoxic properties [25-29]. Such properties are mainly ascribed to its antioxidant activity and its ability to promote cellular mitochondrial functions [30-32]. In this regard, we previously showed in vitro, and for the first time, that PUN is also able to protect RPE from oxidative damage via the Kelch-like ECH-associated protein-1/nuclear factor erythroid 2-related factor 2 /antioxidant responsive elements (Keap/Nrf2/ARE) signaling pathway, confirming its antioxidant properties at the ocular level [33]. However, a better understanding of the mechanisms underlying PUN's antioxidant activity in the RPE could provide the scientific basis for new therapeutic strategies and options for the prevention or delay of the pathological progression of retinal degenerative diseases. Therefore, the goal of this study was to gain further insight into the potential antioxidant role of PUN in the regulation of mitochondrial function. To this purpose, we used an in vitro $\mathrm{H}_{2} \mathrm{O}_{2}$-induced oxidative damage model based on a human-RPE cell line (h-ARPE 19), which was previously developed and validated by our group [34]. Hence, we examined the relationships among PUN pre-treatment $(24 \mathrm{~h})$ and cellular vitality, mitochondrial ROS production, mitochondrial membrane potential $(\Delta \Psi \mathrm{m})$, and activation of caspase-3 in order to determine a possible functional link between the antioxidant effect of PUN supplementation and modulation of mitochondrial function in RPE cells. Moreover, the activity modulation of mitochondrial respiratory complexes by PUN was also investigated. From the present study, it emerges that PUN is an effective and promising mitochondria-targeting antioxidant nutraceutical.

\section{Materials and Methods}

\subsection{Cell Line and Treatments}

ARPE-19 cells (a human RPE cell line) were purchased from the American Type Cell Culture (ATCC-CRL-2302, Manassas, VA, USA). The cells were cultured in basal DMEM/F12 medium (SIGMA D6421; Merck Life Science S.r.l. Milano Italy) supplemented with 10\% FBS (Gibco; Thermo Fisher Scientific, Inc., Waltham, MA, USA) and $100 \mathrm{U} / \mathrm{mL}$ penicillin-streptomycin in a humidified environment containing $5 \% \mathrm{CO}_{2}$. Once $80 \%$ confluence was achieved, the cells were subcultured and used at a concentration of 50,000 cells $/ \mathrm{cm}^{2}$ in all experimental conditions, except where required eventually by experimental procedures for the commercial kit.

The cells were pre-treated with punicalagin (PUN) $24 \mathrm{~h}$ before inducing damage with hydrogen peroxide $\left(\mathrm{H}_{2} \mathrm{O}_{2}\right)$. PUN powder (Sigma-Aldrich, St. Louis, MO, USA) was dissolved in ethanol to obtain $10 \mathrm{mM}$ stock solution; further dilutions were made in the incubation medium. All solutions were freshly prepared before each experiment.

\subsection{Cell Viability}

The cell viability was assessed using the MTS assay (Promega srl-Padova-Italy) [35]. In brief, ARPE-19 cells were collected and seeded into 96-well plates at a density of 
10,000 cells/well and incubated for $24 \mathrm{~h}$ in the presence of increasing concentrations of $\mathrm{H}_{2} \mathrm{O}_{2}$ (range: $25-400 \mu \mathrm{M}$ ). Cell viability was determined by measuring absorbance at $490 \mathrm{~nm}$ using a microplate photometer (BioTek ${ }^{\mathrm{TM}}$ Elx800-Box 998; BioTek Instruments, Winooski, VT, USA). In the same experimental paradigm, once the optimal cytotoxic concentration was determined, the cells were pre-treated $(24 \mathrm{~h})$ with punicalagin at increasing doses (range: $0.5-40 \mu \mathrm{M}$ ) and subsequently treated with $250 \mu \mathrm{M}$ of $\mathrm{H}_{2} \mathrm{O}_{2}$ for a further $24 \mathrm{~h}$. Results are expressed as the percentage of cell viability relative to the untreated control.

\subsection{Mitochondria Purification}

Mitochondria were isolated from ARPE-19 cells using a Mitochondria/Cytosol Fractionation Kit (MBL, Medical and Biological Laboratories, 200 Dexter Ave., Watertown, MA 02472, USA), according to the supplier's instructions. Briefly, $50 \times 106$ pellet cells were incubated at $4{ }^{\circ} \mathrm{C}$ for $10 \mathrm{~min}$ with $1.0 \mathrm{~mL}$ of cytosol extraction buffer mix. Subsequently, the cells were homogenized and centrifuged at $800 \times g$ for $10 \mathrm{~min}$ to remove unbroken cells and nuclei. The supernatant was collected and centrifuged at $15,000 \times g$ for $10 \mathrm{~min}$ at $4{ }^{\circ} \mathrm{C}$. The pellet fraction was solubilized in mitochondrial extraction buffer mix. Protein concentrations were determined using the Thermo Scientific ${ }^{\mathrm{TM}}$ Pierce $^{\mathrm{TM}}$ BCA Protein Assay Kit (Thermo Fisher Scientific, 3747 N. Meridian Road, Rockford, IL 61101, USA).

\subsection{Mitochondria ROS Detection}

A Mitochondrial ROS Detection Assay Kit (Item \# 701600, Cayman Chemical) was used according to the manufacturer's protocol. The kit is targeted primarily for use in distinguishing mitochondrial ROS from cytoplasmic ones. Briefly, ARPE-19 cells were cultured in a 96-well microplate (25,000 cells per well) and treated at the different experimental conditions. Successively the cells were treated with dihydroethidium (DHE), which is a redox-sensitive fluorescent probe primarily targeting the mitochondrion, and with antimycin A as a positive control for ROS generation. After incubation at $37^{\circ} \mathrm{C}$ for $1 \mathrm{~h}$, fluorescence was quantified (excitation wavelength of $480 \mathrm{~nm}$ and emission of wavelength $560 \mathrm{~nm}$ ) using a CytoFluor multi-well plate reader (Victor3-Wallac-1420; PerkinElmer, Waltham, MA, USA). Mitochondrial ROS production was expressed as the fluorescence intensity and presented as a percentage relative to the untreated control.

\subsection{Confocal Microscopy Imaging and Evaluation of Mitochondrial Membrane Potential}

Confocal imaging was performed with a Nikon A1-MP confocal microscope. First, $1 \mu \mathrm{L}$ of JC-9 $1 \mathrm{mM}$ stock solution (Molecular Probes Inc., Eugene, OR, USA) was added per milliliter of culture medium. For the evaluation of mitochondrial membrane potential, images were acquired in two separated channels (excitation: $488 \mathrm{~nm}$, emission: 525/50 nm for the green channel and 595/50 $\mathrm{nm}$ for the red channel). The red/green fluorescent ratio, which reflects variations in mitochondrial membrane potential, was calculated as:

$$
\frac{R}{G}=\frac{I_{R}}{I_{G}}
$$

where $I_{R}$ and $I_{G}$ are the fluorescence emission intensities in the red and green channels, respectively [36,37]. The gain from the detectors and the laser intensity were kept fixed in all the experiments. Mitochondrial depolarization, indicated by a blue shift, corresponds to a decrease in the red/green fluorescent ratio, while a hyperpolarization results in an increased ratio [38].

\subsection{Mitochondrial Complex I-IV Activity Measurements}

The oxidative phosphorylation complex enzymatic activities of mitochondria were measured using specific assay kits according to the manufacturers' protocols.

Mitochondrial respiratory complex I [Nicotinamide adenine dinucleotide reduced (NADH) oxidase/co-enzyme $\mathrm{Q}$ reductase] activity was determined using $20 \mathrm{mg}$ of mitochondrial protein with the MitoCheck Complex I Activity Assay Kit (Cayman Chemicals; 
catalogue no. 700930 Ann Arbor, MI, USA). Mitochondrial complex I activity was determined by measuring the decrease in NADH oxidation, which is reflected by a decreased in absorbance at $340 \mathrm{~nm}$, in the presence of antimycin A (10 M) to ensure inhibition of complex III.

Activity of mitochondrial complex II (succinate dehydrogenase/co-enzyme Q reductase) was assessed by the rate of reduction of 2,6-dichlorophenolindophenol (DCPIP), which is protonated by reduced co-enzyme Q (Cayman Chemical n 700940, Ann Arbor, MI, USA) and is reflected by a decrease in absorbance at $600 \mathrm{~nm}$.

Mitochondrial complex III (co-enzyme Q cytochrome c oxidoreductase) activity was determined by the rate of cytochrome c reduction, which is reflected by increased absorbance at $550 \mathrm{~nm}$ (Cayman Chemical $\mathrm{n}^{\circ}$ 700950, Ann Arbor, MI, USA). To prevent the backflow of electrons through complex I and the reduction of cytochrome c by complex $\mathrm{IV}$, activity measurements were performed in the presence of $1 \mathrm{mM}$ rotenone and $2 \mathrm{mM}$ sodium azide.

The activity of mitochondrial complex IV (cytochrome c oxidase) was determined by measuring the rate of oxidation of cytochrome $c$, which is reflected by a decrease in absorbance at $550 \mathrm{~nm}$ (Cayman Chemical n 700990, Ann Arbor, MI, USA).

The activities of respiratory complexes are shown as percentage changes over controls $(100 \%)$.

\subsection{Measurement of Caspase-3 Activity}

ARPE-19 cells were plated in petri dishes at a seeding density of $3 \times 10^{6}$ cells $/ 35 \mathrm{~mm}$ dish; after treatment, cells were harvested by centrifugation. The pellets were washed with PBS, lysed in $50 \mathrm{~mL}$ of chilled cell lysis buffer, and left on ice for $10 \mathrm{~min}$. Subsequently, the lysates ware centrifuged at $10,000 \times \mathrm{g}$ for $1 \mathrm{~min}$ at $4{ }^{\circ} \mathrm{C}$, and the supernatants were used to assess the caspase- 3 assay. The protein concentration in each lysate was measured using a Bicinchoninic Acid (BCA) Protein Assay Kit from Thermo Scientific ${ }^{\mathrm{TM}}$ Pierce (Thermo Fisher Scientific | 3747 N. Meridian Road | Rockford, IL 61101, USA).

Caspase-3 activity was determined by using a specific colorimetric assay kit from Sigma Chemical Co. (St. Louis, MO, USA) according to the manufacture's protocol. DEVDpNA (Asp-Glu-Val-Asp para-nitroanilide) was used as a colorimetric substrate. The assay was based on spectrophotometric detection of the chromophore p-nitroaniline (pNA) after the caspase-dependent cleavage from the labeled substrate DEVD-pNA using active caspase-3. Caspase-3 activity was determined by quantification of the free pNA using a plate reader at a wavelength of $405 \mathrm{~nm}$. The obtained values were expressed as a percentage relative to the untreated control.

\subsection{Statistical Analysis}

All results are shown as the mean \pm SEM (standard error of the mean) of (n) replicates for each experimental group. Each experiment was repeated at least two times in triplicate unless stated otherwise. Significant differences between groups were calculated using one-way analysis of variance (ANOVA) with a subsequent Dunnet or Newman-Keuls post hoc test for comparisons between group means. All data were analyzed using Prism software version 5.1 (GraphPad, Inc., La Jolla, CA, USA). Differences were considered statistically significant at $p<0.05$.

\section{Results}

\subsection{Punicalagin Pre-Treatment Attenuates $\mathrm{H}_{2} \mathrm{O}_{2}$-Induced Cell Death and Mitochondrial Oxidative Damage}

Human ARPE-19 cell culture was chosen in this study because it is a specific and widely used in vitro experimental model for the study of RPE neurodegenerative diseases. The study's first set of planned experiments was carried out to investigate the inhibition rate of cell growth by $\mathrm{H}_{2} \mathrm{O}_{2}$ in ARPE-19 cells using an MTS assay. In dose-response experiments, $\mathrm{H}_{2} \mathrm{O}_{2}$ was administered in a dose range of 25 to $400 \mu \mathrm{M}$ for $24 \mathrm{~h}$. Find- 
ings obtained via MTS assay (Figure 1A) highlighted that the rate of cell growth inhibition was directly proportional to the concentration of $\mathrm{H}_{2} \mathrm{O}_{2}$. In particular, the results showed that cell inhibition was approximately $50 \%(53.5 \% \pm 3.677 \mathrm{n}=6)$ at a concentration of $250 \mu \mathrm{M}$. Therefore, the subsequent experiments were conducted using this concentration to induce cytotoxicity.
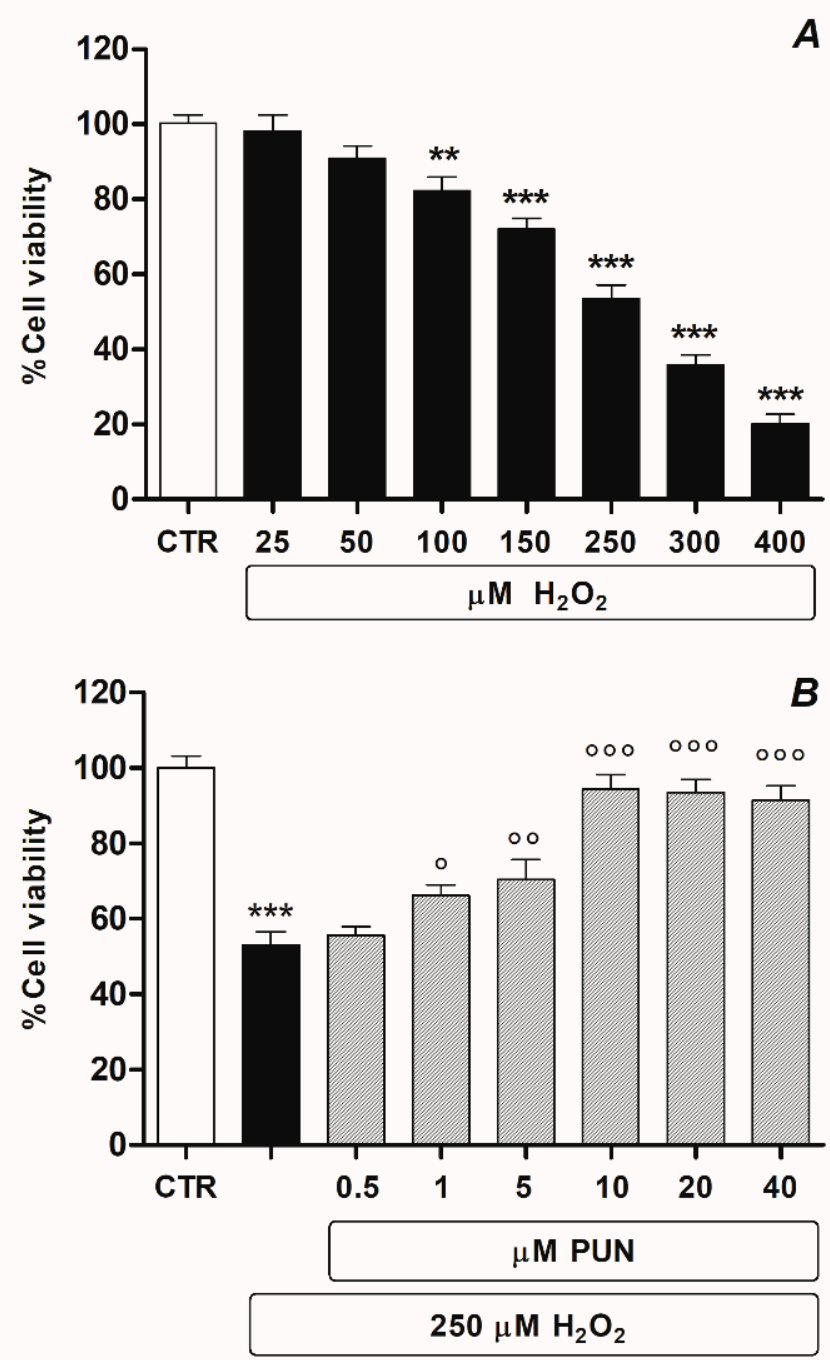

Figure 1. Viability of ARPE-19 cells treated with $\mathrm{H}_{2} \mathrm{O}_{2}$ (range 25-400 $\mu \mathrm{M}$ ) for $24 \mathrm{~h}(\mathbf{A})$ and protective effect of $24 \mathrm{~h}$ pre-treatment with multidose PUN (range 0.5-40 $\mu \mathrm{M})(\mathbf{B})$. Data from two independent experiments are expressed as percentage viability values with respect to untreated cells (control $=100 \%)$ and are presented as the mean \pm SEM of six replicates per experimental group. Oneway ANOVA analysis was carried out followed by Dunnett's or Newman-Keuls test for multiple comparisons with a control or for pairwise comparisons among sample means. Note: ${ }^{* *}=p<0.01$ and $^{* * *}=p<0.001$ vs. untreated control; ${ }^{\circ}=p<0.05,{ }^{\circ}=p<0.01,{ }^{\circ}{ }^{\circ 0}=p<0.001$ vs. $\mathrm{H}_{2} \mathrm{O}_{2}$ alone.

Subsequently, experiments were performed in order to evaluate whether or not PUN was capable of reducing $\mathrm{H}_{2} \mathrm{O}_{2}$ cytotoxicity in our experimental model. Dose-response experiments were conducted with PUN in the range of $0.5-40 \mu \mathrm{M}$ in the presence of $250 \mu \mathrm{M} \mathrm{H}_{2} \mathrm{O}_{2}$. ARPE-19 cells pre-treated ( $24 \mathrm{~h}$ ) with PUN and afterward incubated with $\mathrm{H}_{2} \mathrm{O}_{2}\left(24 \mathrm{~h}\right.$ ) showed significantly attenuated $\mathrm{H}_{2} \mathrm{O}_{2}$-induced cytotoxicity compared to cells exposed to only $\mathrm{H}_{2} \mathrm{O}_{2}$ alone. The observed protective effect of PUN was concentrationdependent, recovering cell viability of over $90 \%(94.3 \% \pm 3.88 \mathrm{n}=6)$ at a concentration of $10 \mu \mathrm{M}$ (Figure 1B). 
In light of the obtained results, the subsequent experiments were conducted with the following experimental protocol: pre-treatment with $10 \mu \mathrm{M}$ PUN for $24 \mathrm{~h}$ followed by the addition of $\mathrm{H}_{2} \mathrm{O}_{2}$ for a further $24 \mathrm{~h}$, except for control groups treated with medium, PUN, or $\mathrm{H}_{2} \mathrm{O}_{2}$ alone.

Next, to unravel if the cytoprotection observed post-PUN treatment was mediated by attenuating mitochondrial ROS, we measured the production of ROS within these organelles in our experimental paradigm. Under these conditions, pre-treatment with PUN was able to reduce $\mathrm{H}_{2} \mathrm{O}_{2}$-induced ROS mitochondrial levels (control: $100.0 \% \pm 3.25, \mathrm{n}=6$; PUN: $97.17 \% \pm 4.06, \mathrm{n}=6 ; \mathrm{H}_{2} \mathrm{O}_{2}: 172.67 \% \pm 6.32, \mathrm{n}=6 ; \mathrm{H}_{2} \mathrm{O}_{2}+$ PUN $111.93 \pm 3.51, \mathrm{n}=6$ ) (Figure 2).

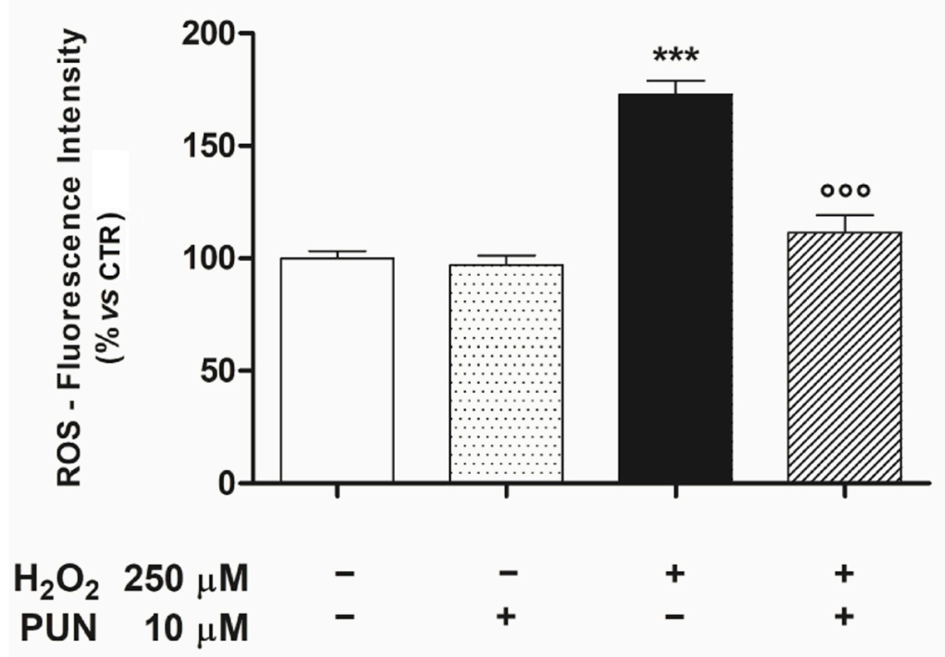

Figure 2. It was possible to reduce the $\mathrm{H}_{2} \mathrm{O}_{2}$-induced increase of mitochondrial ROS levels by pre-treating the ARPE-19 cells with PUN for $24 \mathrm{~h}$. Values are expressed as percentages relative to the untreated control $(100 \%)$ and are presented as means \pm SEM of data from two distinct experiments, each in quadruplicate. One-way ANOVA analysis was carried out followed by post hoc NewmanKeuls test. Note: ${ }^{* * *}=p<0.001$ vs. control; ${ }^{\circ 00}=p<0.001$ vs. $250 \mu \mathrm{M} \mathrm{H}_{2} \mathrm{O}_{2}$ alone.

\subsection{Effect of Punicalagin on $\mathrm{H}_{2} \mathrm{O}_{2}$-Induced Reduction of Mitochondrial Membrane Potential}

RPE cells are an energy-intensive cell type and mitochondria are their main source of energy. Since mitochondrial dysfunction is an early event in the $\mathrm{H}_{2} \mathrm{O}_{2}$-induced cell death process, we examined mitochondrial membrane potential in $\mathrm{H}_{2} \mathrm{O}_{2}$-treated ARPE-19 cells, with or without punicalagin pre-treatment, using confocal microscopy imaging.

JC-9 is a ratiometric cationic dye characterized by its potential-dependent accumulation in mitochondria, which is indicated by a shift in the fluorescence emission from green $(\sim 525 \mathrm{~nm})$ to red $(\sim 590 \mathrm{~nm})$ [39]. This potential-sensitive color is due to the concentrationdependent formation of J-aggregates and variations in the red/green fluorescence intensity ratio, being dependent only on the membrane potential and not on other factors such as the mitochondrial size, shape, and density. It provides an indicator for mitochondrial depolarization, which occurs in the early stage of apoptosis, and allows the responses of cells to an applied stimulus to be assessed [40].

The panel in Figure 3 shows representative confocal images of untreated ARPE-19 cells (CTR; Figure 3A), cells treated with $10 \mu \mathrm{M}$ punicalagin (PUN; Figure 3B), cells treated with $250 \mu \mathrm{M}$ hydrogen peroxide $\left(\mathrm{H}_{2} \mathrm{O}_{2} ;\right.$ Figure $\left.3 \mathrm{C}\right)$, or cells pre-treated with punicalagin $24 \mathrm{~h}$ before $\mathrm{H}_{2} \mathrm{O}_{2}$ (PUN $+\mathrm{H}_{2} \mathrm{O}_{2}$; Figure 3D). In the first row, composite dual-channel images are reported along with a magnification of CTR, PUN, $\mathrm{H}_{2} \mathrm{O}_{2}$, and $\mathrm{PUN}+\mathrm{H}_{2} \mathrm{O}_{2}$ images, respectively (Figure 3E-H). The green channel (emission: 525/50 nm) indicates the fluorescence intensity from monomers, while the red channel (emission: 590/50 nm) represents the emissions from J-aggregates. Representative maps of the red/green fluorescence intensity ratio for CTR, PUN, $\mathrm{H}_{2} \mathrm{O}_{2}$, and $\mathrm{PUN}+\mathrm{H}_{2} \mathrm{O}_{2}$ cells are shown in Figure 3I-L, 
respectively, where each pixel is colored according to the red/green intensity ratio, ranging from light purple (low $\mathrm{R} / \mathrm{G}$ emission intensity ratio, mitochondrial depolarization) to yellow (high $\mathrm{R} / \mathrm{G}$ emission intensity ratio, mitochondrial hyperpolarization). Mean values \pm standard deviations of the ratio are summarized in the bar plot reported alongside with the images (Figure 3M).

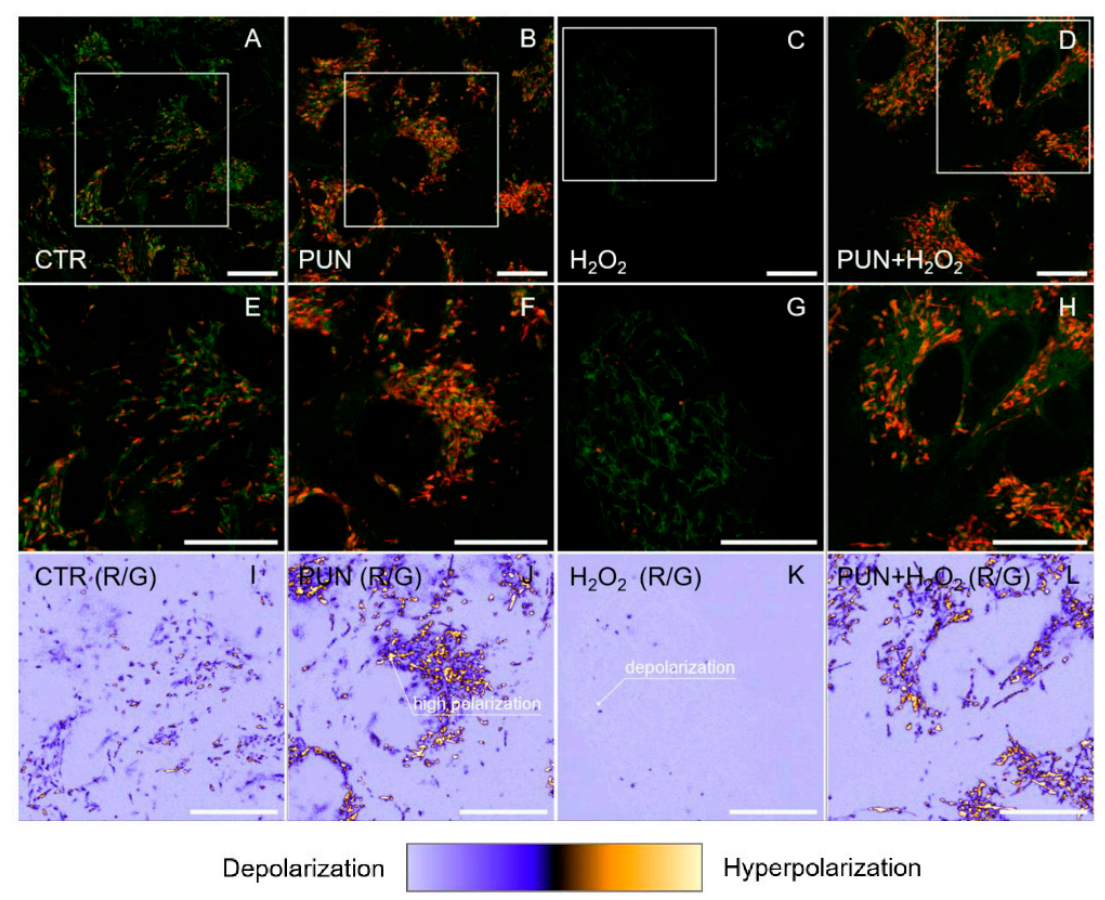

$\mathrm{M}$

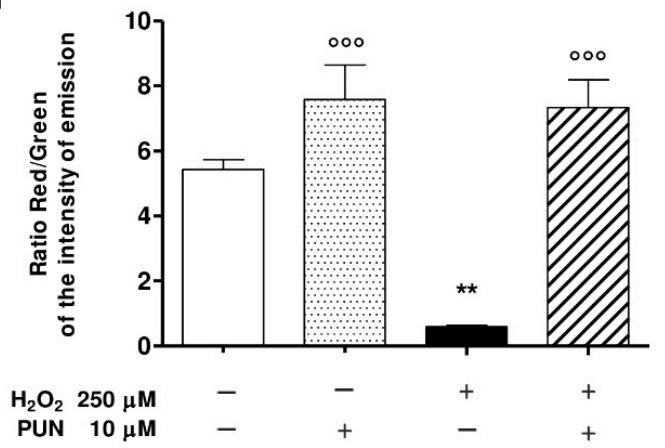

Figure 3. Representative confocal images of ARPE-19 cells untreated (CTR, first column), treated with $10 \mu \mathrm{M}$ punicalagin (PUN, second column), treated with $250 \mu \mathrm{M}$ hydrogen peroxide $\left(\mathrm{H}_{2} \mathrm{O}_{2}\right.$, third column), or pre-treated with punicalagin $24 \mathrm{~h}$ before $\mathrm{H}_{2} \mathrm{O}_{2}$ ( $\mathrm{PUN}+\mathrm{H}_{2} \mathrm{O}_{2}$, fourth column). Composite dual-channel images (A-D) are shown in the first row, along with a magnification of CTR (E), PUN (F), $\mathrm{H}_{2} \mathrm{O}_{2}(\mathbf{G})$, and PUN $+\mathrm{H}_{2} \mathrm{O}_{2}(\mathbf{H})$, respectively. The green channel (emission: 525/50 nm) indicates the fluorescence intensity from monomers, while the red channel (emission: 595/50 nm) represents the emissions from aggregates. In the third row, representative maps of the red/green fluorescence intensity ratio (indicated as R/G) are reported for CTR (I), PUN (J), $\mathrm{H}_{2} \mathrm{O}_{2}(\mathbf{K})$, and PUN+ $\mathrm{H}_{2} \mathrm{O}_{2}$ (L), respectively. Each pixel's color spans from light purple (low R/G emission intensity ratio, mitochondrial depolarization) to yellow (high $\mathrm{R} / \mathrm{G}$ emission intensity ratio, mitochondrial hyperpolarization). Values of the emission intensity ratio range from 0 to 15 . The means \pm 1 SEM of the ratio are summarized in the bar plot reported in (M). Results are from two independent experiments, each including three replicates per experimental group. One-way ANOVA analysis was carried out followed by post hoc Newman-Keuls test. ${ }^{* *}=p<0.01$ vs. control; ${ }^{\circ \circ \circ}=p<0.001 \mathrm{vs} .250 \mu \mathrm{M}$ $\mathrm{H}_{2} \mathrm{O}_{2}$ alone. 
At this point of the study, and supported by the results of our previous study [33], we hypothesized that PUN's effect on the mitochondrial membrane potential, both in terms of the basal conditions and in the presence of $\mathrm{H}_{2} \mathrm{O}_{2}$, is caused by the upstream activation of Keap1-Nrf2 antioxidant defence system. In fact, it is well known that Nrf2 can influence many aspects of mitochondrial physiology, including increasing the mitochondrial membrane potential [41,42].

Treating cells with $250 \mu \mathrm{M} \mathrm{H}_{2} \mathrm{O}_{2}$ (Figure 3C) induced strong mitochondrial depolarization, as represented in Figure 3 (Figure $3 \mathrm{G}, \mathrm{K}$ ). In particular, comparing the value of the red/green emission intensity ratios for CTR and $\mathrm{H}_{2} \mathrm{O}_{2}$ cells (Figure 3I,K, respectively), a decrease from $5.43 \pm 0.54$ for the CTR to $0.60 \pm 0.08$ for $\mathrm{H}_{2} \mathrm{O}_{2}$ was observed. Looking at Figure $3 \mathrm{~B}$ and the magnified view in Figure $3 \mathrm{~F}$, it is possible to observe a higher presence of J-aggregates (red emission) compared to CTR (Figure 3A,E), corresponding to an increase in the R/G emission ratio, as clearly represented in Figure 3I, J, respectively. This suggests a potential protective effect of punicalagin, which can also be achieved in the presence of a subsequent treatment with $\mathrm{H}_{2} \mathrm{O}_{2}$, as shown in Figure 3D,H,L. In this case, although a slight decrease in the $\mathrm{R} / \mathrm{G}$ ratio from $7.58 \pm 1.84$ (pre-treatment with punicalagin) to $7.34 \pm 1.48$ $\left(\mathrm{H}_{2} \mathrm{O}_{2} 24 \mathrm{~h}\right.$ after punicalagin pre-treatment) was detected, a significant increase in polarization can be observed with respect to CTR. Overall, these data show that mitochondrial hyperpolarization occurred in both pre-treated samples (PUN and PUN $+\mathrm{H}_{2} \mathrm{O}_{2}$ ).

\subsection{Protective Effect of PUN Supplementation on $\mathrm{H}_{2} \mathrm{O}_{2}$-Induced Respiratory Chain Dysfunction in ARPE-19 Cell Mitochondria}

A second series of experiments was performed to investigate whether the protective effect of PUN, as previously observed for $\mathrm{H}_{2} \mathrm{O}_{2}$-induced mitochondrial depolarization, was also extended to the mitochondrial respiratory chain. Therefore, enzymatic activities of mitochondrial complexes I (NADH-ubiquinone oxidoreductase), II (Succinate dehydrogenase), III (ubiquinone-cytochrome c oxidoreductase), and IV (cytochrome c oxidase) were assessed in mitochondrial fractions of the ARPE-19 cells in our experimental paradigm.

The enzyme activities of mitochondrial complexes I, III, and IV, as displayed in Figure 4, were significantly reduced after exposure to $250 \mu \mathrm{M} \mathrm{H}_{2} \mathrm{O}_{2}$ for $24 \mathrm{~h}$ compared to the control group related to each single complex $(p<0.001, p<0.05$, and $p<0.01$, respectively). Interestingly, pre-treatment (for $24 \mathrm{~h}$ ) with PUN antagonized $\mathrm{H}_{2} \mathrm{O}_{2}$-mediated respiratory chain dysfunction by restoring the enzymatic activity of the respiratory complexes almost to the levels of controls not exposed to oxidative damage (complex I: control: 100.0\% \pm 3.25; PUN: $97.9 \% \pm 3.53 ; \mathrm{H}_{2} \mathrm{O}_{2}$ : 70.73\% $\pm 4.52 ; \mathrm{H}_{2} \mathrm{O}_{2}+$ PUN $94.79 \pm 3.51$; complex III: control: $100.0 \% \pm 5.97 ; \mathrm{PUN}$ : $93.88 \% \pm 4.78 ; \mathrm{H}_{2} \mathrm{O}_{2}: 75.02 \% \pm 5.55 ; \mathrm{H}_{2} \mathrm{O}_{2}+\mathrm{PUN}$ $95.00 \pm 5.01$; complex IV: control: $100.0 \% \pm 4.41 ; \mathrm{PUN}$ : 92.53\% $\pm 5.78 ; \mathrm{H}_{2} \mathrm{O}_{2}: 67.67 \% \pm 6.57$; $\mathrm{H}_{2} \mathrm{O}_{2}+\mathrm{PUN} 91.33 \pm 5.99$. Six replicates in each experimental group). Conversely, no significant differences between the experimental groups were observed for complex II in our experimental paradigm (control: $100.0 \% \pm 3.24 \mathrm{n}=6$; PUN: $97.6 \% \pm 5.31 \mathrm{n}=6 ; \mathrm{H}_{2} \mathrm{O}_{2}$ : $96.7 \% \pm 5.54 \mathrm{n}=6 ; \mathrm{H}_{2} \mathrm{O}_{2}+\mathrm{PUN} 98.83 \pm 4.60 \mathrm{n}=6$ ). Furthermore, it should be noted that contrary to what was seen in the other complexes, the values obtained for complex II were very close to the detection limit of the dosage.

Pre-treatment with punicalagin resulted in no significant changes in mitochondrial respiratory activity in the absence of the oxidative stimulus compared to the control group related to each single complex (Figure 4).

\subsection{Punicalagin Pre-Treatment Inhibits $\mathrm{H}_{2} \mathrm{O}_{2}$-Induced Caspase-3 Enzymatic Activity}

Oxidative damage linked to the permeabilization of the mitochondrial outer membrane causes the release of cytochrome $c$, which activates a family of proteases, named caspases. Among these, caspase-3 in particular amplifies the cell death signal. Consequently, we examined if PUN was able to modulate the $\mathrm{H}_{2} \mathrm{O}_{2}$-induced activity of caspase- 3 in our experimental paradigm. A significant and consistent increase of caspase-3 activity was elicited by oxidative stimulus $\left(250 \mu \mathrm{M} \mathrm{H}_{2} \mathrm{O}_{2}\right)$ after $24 \mathrm{~h}$ of incubation in ARPE-19 cells. As shown in Figure 5, caspase-3 activity was increased by 2.7 -fold in the $\mathrm{H}_{2} \mathrm{O}_{2}$-treated 
group compared to the untreated control group. Under these conditions, pre-treatment with $10 \mu \mathrm{M}$ PUN for $24 \mathrm{~h}$ was able to inhibit the enzymatic activity of the caspase-3 stimulated by oxidative damage, bringing it back to the untreated control levels (Figure 5). At the same concentration $(10 \mu \mathrm{M})$, PUN did not affect the basal enzymatic activity of caspase-3 (Figure 5).

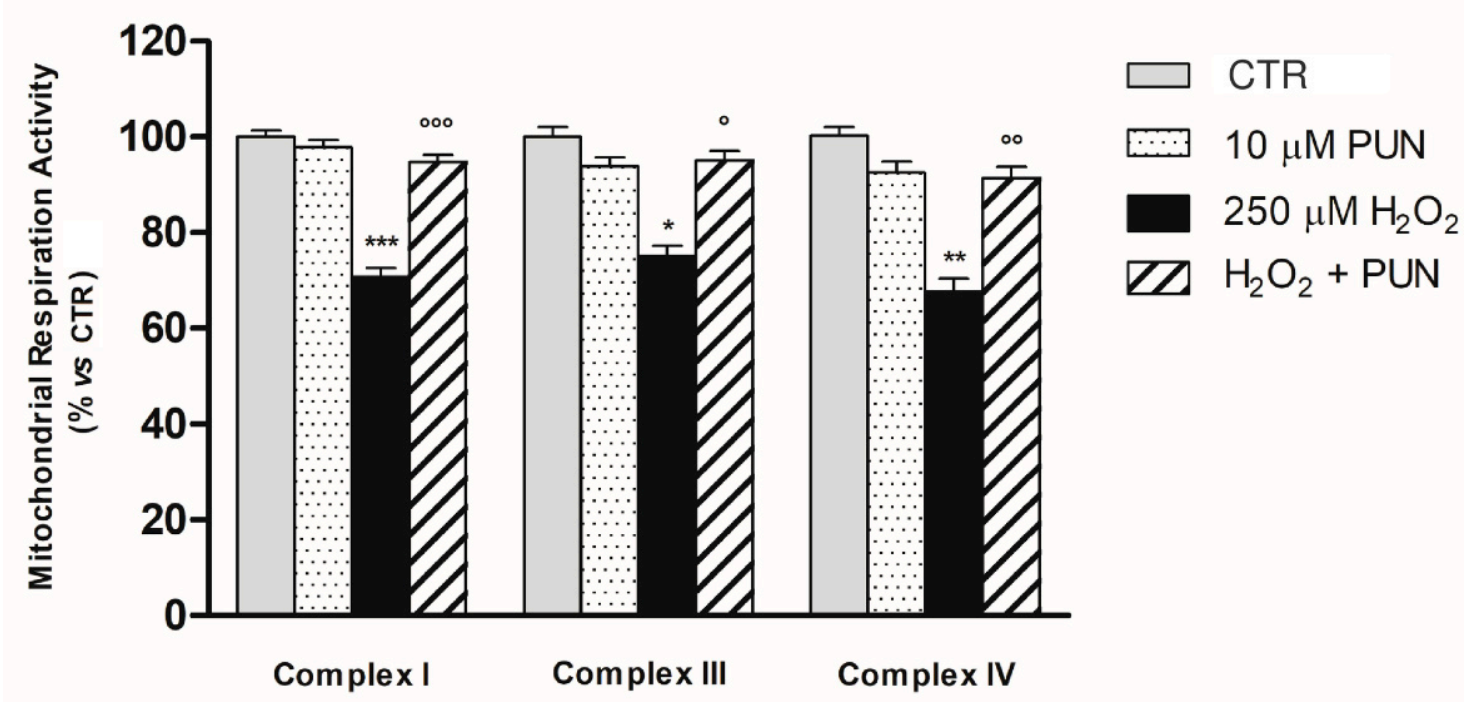

Figure 4. The activities of mitochondrial respiratory chain complexes I, III, and IV were measured in mitochondria isolated of ARPE-19 cells. Enzyme activities were determined using specific assay kits (see Section 2.6 in Material and Methods). Results are shown as percentages relative to control for the single complex, which was set at $100 \%$. Data are presented as the mean \pm SEM of six replicates per experimental group from two independent experiments. One-way ANOVA analysis was carried out followed by post hoc Newman-Keuls test for each single respiratory complex. ${ }^{*}, p<0.05$; ${ }^{* *}=p<0.01$ and ${ }^{* * *}=p<0.001$ vs. Control $;^{\circ}=p<0.05 ;^{\circ \circ}=p<0.01$ and ${ }^{\circ \circ \circ}=p<0.001$ vs. $\mathrm{H}_{2} \mathrm{O}_{2}(250 \mu \mathrm{M})$ alone.

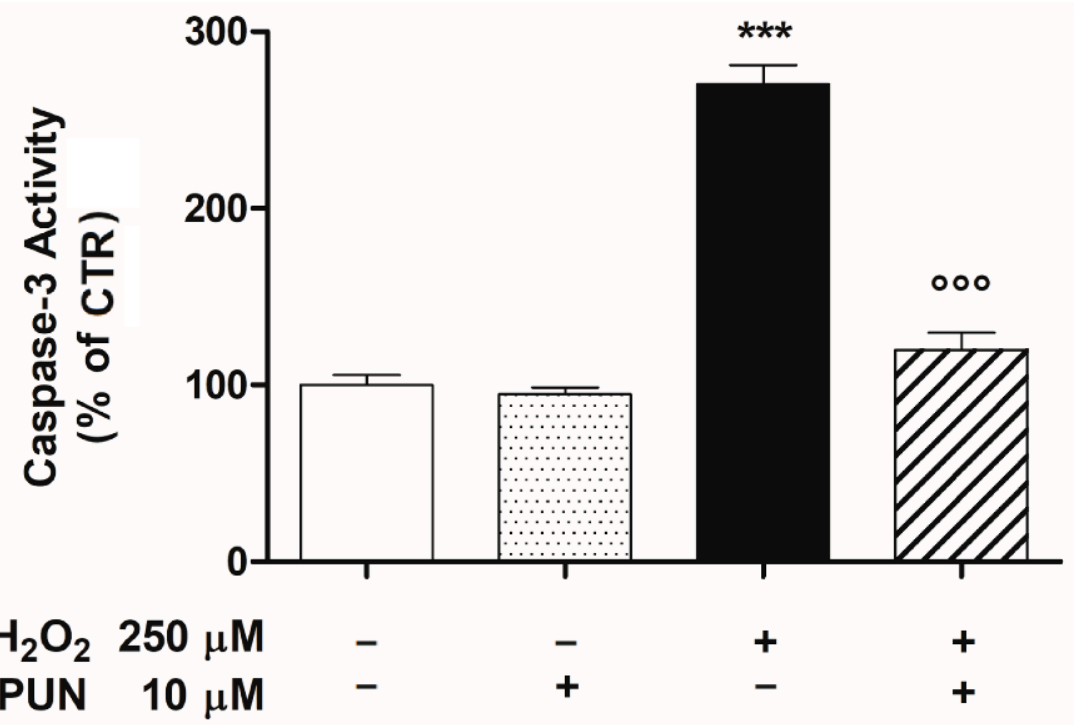

Figure 5. Pre-treatment with $10 \mu \mathrm{M}$ punicalagin (PUN) for $24 \mathrm{~h}$ downregulated the $\mathrm{H}_{2} \mathrm{O}_{2}$-induced caspase-3 activity in ARPE-19 cells. Data are expressed as a percentage relative to the untreated cells (control $=100 \%$ ) and are presented as the means \pm SEM of 6 replicates per group from two independent experiments. One-way ANOVA analysis was carried out followed by post hoc NewmanKeuls test. ${ }^{* * *} p<0.001$ vs. Control; ${ }^{\circ 00} p<0.001$ vs. $\mathrm{H}_{2} \mathrm{O}_{2}$ alone. 


\section{Discussion}

Both exogenous and endogenous oxidizing agents can cause oxidative stress in RPE, triggering the cascade of pathological events underlying the onset of numerous retinal neurodegenerative diseases, such as age-related macular degeneration, retinitis pigmentosa, and diabetic retinopathy [43]. The oxidative stress process is driven by an imbalance between pro-oxidant species and antioxidant defenses, which leads to a progressive alteration of the redox regulation signaling mechanisms associated with ROS production increases. A high production level of ROS leads to cellular dysfunctions mainly in the mitochondria, which lose their membrane integrity, with consequent dissipation of the mitochondrial membrane potential $(\Delta \Psi \mathrm{m})$ and malfunction of the respiratory complexes [44,45]. Therefore, the attempt to counteract the overproduction of ROS, which are considered the mediators of oxidative damage, is one of the most studied approaches for preserving RPE functional integrity upon oxidative stress [46]. Emerging research evidence suggests that natural antioxidant compounds, especially polyphenols and carotenoids, could reduce oxidative stress in RPE [47,48].

Punicalagin, a polyphenolic phytochemical responsible for more than the half of pomegranate juice's antioxidant effects, possesses a wide range of biological activities in numerous different tissues and cell types [26-28,49]. Recently, our group demonstrated for the first time that PUN also has antioxidant properties in RPE, lowering exogenous oxidativedamage-induced ROS levels and improving cell viability via the Keap/Nrf2/ARE signaling pathway [33]. In the present study, we reinforce this hypothesis by extending the antioxidant action range of the PUN to the mitochondria of RPE cells.

The RPE cell oxidative stress model used in this study was obtained by treatment with $250 \mu \mathrm{M} \mathrm{H}_{2} \mathrm{O}_{2}$ for $24 \mathrm{~h}$ on the human-RPE cell line ARPE-19. This is a widely used model for in vitro studies of oxidative damage $[34,50,51]$. We report here that the $\mathrm{H}_{2} \mathrm{O}_{2}$ treatment markedly reduced the cellular viability and promoted mitochondrial dysfunction due to an increase of ROS mitochondrial levels and a reduction of mitochondrial membrane potential. However, these pathological changes were antagonized by pre-treatment for 24 with $10 \mu \mathrm{M}$ PUN before the oxidative damage by $\mathrm{H}_{2} \mathrm{O}_{2}$, confirming the protective properties of the compound in RPE cells [33]. In particular, we found that PUN decreased $\mathrm{H}_{2} \mathrm{O}_{2}$-induced ROS generation and improved mitochondrial function, completely reversing mitochondrial membrane potential loss caused by the oxidative stimulus. This suggests that PUN can possibly restore mitochondrial respiratory chain activity in RPE cells.

The maintenance of mitochondrial viability depends on the ability of the mitochondria to detect changes in the redox state and respond commensurately to metabolic requests. During oxidative phosphorylation, electrons flow from the reduced state to the oxidized state along the electron transport chain, which is embedded in the inner mitochondrial membrane. The energy released by the flow of electrons (through complexes I, III, and IV) is used to pump hydrogen ions from the mitochondrial matrix to the intermembrane space, creating a concentration gradient that is positive on the outside and negative on the inside. [52,53]. If cellular respiration is slow or stops, the gradient created by cellular respiration fails, the produced energy decreases, and finally the cells die [54]. Our results clearly showed that PUN preserves the functionality of complexes I, III, and IV, counteracting their activity decline induced by $\mathrm{H}_{2} \mathrm{O}_{2}$. It is intriguing to note that both $\mathrm{H}_{2} \mathrm{O}_{2}$ and PUN had no action on complex II, probably due to its location on the inner mitochondrial membrane, which makes the complex less susceptible to oxidative stress [55]. Interestingly, complexes I, III, and IV have a proton-pumping function. When their activities decrease, the proton pump function is reduced, triggering a decline of mitochondrial membrane potential [56]. In particular, the inhibition of enzymes of complexes I and III increases the production of $\mathrm{O}_{2}{ }^{-}$, causing an increase in oxidative stress. In addition, the reduction of the activity of complex IV, which plays a key role in the regulation of aerobic energy production, can result in compromised membrane potential and a reduced ATP level, and therefore severe mitochondrial dysfunction. 
The oxidative damage linked to the alteration of the outer mitochondrial membrane permeabilization causes the release of cytochrome $\mathrm{c}$ in the cytosol, which promotes the activation of caspases. In particular, cytochrome $c$ induces activation of downstream caspase-3, which triggers apoptosis and processes cellular death. In addition, caspase-3 itself favors further cytochrome $c$ release from mitochondria, which amplifies the death signal $[57,58]$. Consequently, we examined in our experimental paradigm PUN's effects on caspase- 3 activity in RPE cells exposed to $\mathrm{H}_{2} \mathrm{O}_{2}$. Exposure of RPE cells to $\mathrm{H}_{2} \mathrm{O}_{2}$ resulted in a sharp increase of caspase-3 activity, which was antagonized in a significant manner by pre-treatment with PUN $24 \mathrm{~h}$ before the addition of $\mathrm{H}_{2} \mathrm{O}_{2}$. Therefore, these results lead us also to hypothesize that PUN's protective role against apoptosis is induced by the caspase cascade, triggered in turn by deterioration of mitochondrial functions.

The results of the present study on the one hand confirm and reinforce the observations of our previous study [33], while on the other hand provide important new information on the protective role of PUN against oxidative damage in RPE. We hypothesize that the protective mechanism underlying the effect of PUN in RPE has a dual pathway. In fact, it both stimulates cellular antioxidant systems through the $\mathrm{Nrf} 2 / \mathrm{HO}-1$ signaling pathway [33] and protects mitochondria via Nrf2 from oxidative damage by antagonizing mitochondrial dysfunction, which we evaluated in terms of mitochondrial membrane polarization loss and through mitochondrial respiratory chain complex inefficiency. Interestingly, our findings agree with current knowledge about PUN and its antioxidative action via Nrf2 pathways observed in other experimental models in vivo and in vitro $[59,60]$. Furthermore, recent studies have shown that Nrf2 also affects many aspects of mitochondrial physiology, such as the structural integrity and dynamics of this essential organelle [41,42]. However, exogenous $\mathrm{H}_{2} \mathrm{O}_{2}$ binds Keap1 in the cytoplasm, preventing binding and activation of Nrf2 [61]. In this contest, our study shows for the first time that PUN and the Keap/ Nrf2/ARE signaling pathway act in concert to maintain redox homeostasis, protecting the RPE cells from $\mathrm{H}_{2} \mathrm{O}_{2}$-induced oxidative stress [33]. Thus, it can be concluded that PUN has a critical role in maintaining mitochondrial integrity and redox homeostasis under conditions of oxidation. Obviously, further investigations in vitro will be needed to confirm the basic hypothesis of our studies, possibly on other cellular experimental models of RPE that are closer to the natural physiological model than the ARPE-19 model [62-65].

\section{Conclusions}

To the best of our knowledge, our study provides the first evidence that in RPE cells, PUN is able to counter the $\mathrm{H}_{2} \mathrm{O}_{2}$-induced, mitochondrial-dysfunction-associated pathological changes, such as the accumulation of ROS, the membrane potential reduction in mitochondria, and the increase of caspase-3 activity. Therefore, although some questions remain open, it is possible to speculate that mitochondria are targets for PUN antioxidant action in $\mathrm{H}_{2} \mathrm{O}_{2}$-treated RPE cells.

The results of our study add new insights into the molecular mechanisms underlying the antioxidant properties of PUN on RPE exposed to oxidative stress. We hypothesize a synergistic effect of PUN capable of maintaining both redox homeostasis and mitochondrial integrity and functionality, in turn avoiding the caspase cascade and consequent cell death.

Taken together, our findings indicate PUN as an effective nutraceutical agent, supplementation with which could represent a promising therapeutic approach for prophylaxis or treatment of oxidation-associated RPE disorders.

Author Contributions: Conceptualization, G.T. and M.E.C.; methodology, M.E.C., G.T., G.M., and G.B.; validation, M.E.C., G.M., and G.T.; formal analysis, M.E.C., G.M., and G.T.; investigation, M.E.C., G.B., M.P., and B.S.; writing-original draft preparation, G.T., M.E.C., and G.M.; writingreview and editing, G.T. and M.E.C.; visualization, G.T., M.E.C., and G.B.; project administration, G.T. and M.E.C.; funding acquisition, M.E.C. and G.T. All authors have read and agreed to the published version of the manuscript.

Funding: The present study was supported by Italian National Research Council (CNR) funding to M.E.C. and by internal funding (Fondi di Ateneo D1: 2020) to G.T. 
Institutional Review Board Statement: Not applicable.

Informed Consent Statement: Not applicable.

Data Availability Statement: Data are contained within the article.

Conflicts of Interest: The authors declare no conflict of interest.

\section{References}

1. Lakkaraju, A.; Umapathy, A.; Tan, L.X.; Daniele, L.; Philp, N.J.; Boesze-Battaglia, K.; Williams, D.S. The cell biology of the retinal pigment epithelium. Prog. Retin. Eye Res. 2020, 78, 100846. [CrossRef] [PubMed]

2. Strauss, O. The Retinal Pigment Epithelium in Visual Function. Physiol. Rev. 2005, 85, 845-881. [CrossRef] [PubMed]

3. Strauß, O. Pharmacology of the retinal pigment epithelium, the interface between retina and body system. Eur. J. Pharmacol. 2016, 787, 84-93. [CrossRef]

4. Kay, P.; Yang, Y.C.; Paraoan, L. Directional protein secretion by the retinal pigment epithelium: Roles in retinal health and the development of age-related macular degeneration. J. Cell. Mol. Med. 2013, 17, 833-843. [CrossRef] [PubMed]

5. Ponnalagu, M.; Subramani, M.; Jayadev, C.; Shetty, R.; Das, D. Retinal pigment epithelium-secretome: A diabetic retinopathy perspective. Cytokine 2017, 95, 126-135. [CrossRef] [PubMed]

6. Pavan, B.; Dalpiaz, A. Retinal pigment epithelial cells as a therapeutic tool and target against retinopathies. Drug Discov. Today 2018, 23, 1672-1679. [CrossRef]

7. Kaarniranta, K.; Tokarz, P.; Koskela, A.; Paterno, J.; Blasiak, J. Autophagy regulates death of retinal pigment epithelium cells in age-related macular degeneration. Cell Biol. Toxicol. 2017, 33, 113-128. [CrossRef] [PubMed]

8. Cai, J.; Nelson, K.C.; Wu, M.; Sternberg, P.; Jones, D.P. Oxidative damage and protection of the RPE. Prog. Retin. Eye Res. 2000, 19, 205-221. [CrossRef]

9. Seo, S.-J.; Krebs, M.P.; Mao, H.; Jones, K.; Conners, M.; Lewin, A.S. Pathological consequences of long-term mitochondrial oxidative stress in the mouse retinal pigment epithelium. Exp. Eye Res. 2012, 101, 60-71. [CrossRef]

10. Datta, S.; Cano, M.; Ebrahimi, K.; Wang, L.; Handa, J.T. The impact of oxidative stress and inflammation on RPE degeneration in non-neovascular AMD. Prog. Retin. Eye Res. 2017, 60, 201-218. [CrossRef]

11. Birben, E.; Sahiner, U.M.; Sackesen, C.; Erzurum, S.; Kalayci, O. Oxidative stress and antioxidant defence. World Allergy Organ. J. 2012, 5, 9-19. [CrossRef]

12. Tringali, G.; Sampaolese, B.; Clementi, M.E. Expression of early and late cellular damage markers by ARPE-19 cells following prolonged treatment with UV-A radiation. Mol. Med. Rep. 2016, 14, 3485-3489. [CrossRef] [PubMed]

13. Teussink, M.M.; Lambertus, S.; de Mul, F.F.; Rozanowska, M.B.; Hoyng, C.B.; Klevering, B.J.; Theelen, T. Lipofuscin-associated photo-oxidative stress during fundus autofluorescence imaging. PLoS ONE 2017, 12, e0172635. [CrossRef] [PubMed]

14. Brown, E.E.; DeWeerd, A.J.; Ildefonso, C.J.; Lewin, A.S.; Ash, J.D. Mitochondrial oxidative stress in the retinal pigment epithelium (RPE) led to metabolic dysfunction in both the RPE and retinal photoreceptors. Redox Biol. 2019, 24, 101201. [PubMed]

15. Liang, F.-Q.; Godley, B.F. Oxidative stress-induced mitochondrial DNA damage in human retinal pigment epithelial cells: A possible mechanism for RPE aging and age-related macular degeneration. Exp. Eye Res. 2003, 76, 397-403. [CrossRef]

16. Tao, J.-X.; Zhou, W.-C.; Zhu, X.-G. Mitochondria as Potential Targets and Initiators of the Blue Light Hazard to the Retina. Oxidative Med. Cell. Longev. 2019, 2019, 6435364. [CrossRef]

17. Johnsen-Soriano, S.; Garcia-Pous, M.; Arnal, E.; Sancho-Tello, M.; Garcia-Delpech, S.; Miranda, M.; Francisco, B.-M.; Díaz-Llopis, M.; Navea, A.; Romero, F.J. Early lipoic acid intake protects retina of diabetic mice. Free. Radic. Res. 2008, 42, 613-617. [CrossRef]

18. Voloboueva, L.A.; Killilea, D.W.; Atamna, H.; Ames, B.N. N-tert-butyl hydroxylamine, a mitochondrial antioxidant, protects human retinal pigment epithelial cells from iron overload: Relevance to macular degeneration. FASEB J. 2007, 21, 4077-4086. [CrossRef]

19. Suárez-Barrio, C.; del Olmo-Aguado, S.; García-Pérez, E.; de la Fuente, M.; Muruzabal, F.; Anitua, E.; Baamonde-Arbaiza, B.; Fernández-Vega-Cueto, L.; Fernández-García, B.; Jesus, M.-L. Antioxidant Role of PRGF on RPE Cells after Blue Light Insult as a Therapy for Neurodegenerative Diseases. Int. J. Mol. Sci. 2020, 21, 1021. [CrossRef]

20. Gorusupudi, A.; Nelson, K.; Bernstein, P.S. The Age-Related Eye Disease 2 Study: Micronutrients in the Treatment of Macular Degeneration. Adv. Nutr. 2017, 8, 40-53. [CrossRef]

21. Piccardi, M.; Marangoni, D.; Minnella, A.; Savastano, M.C.; Valentini, P.; Ambrosio, L.; Capoluongo, E.; Maccarone, R.; Bisti, S.; Falsini, B. A longitudinal follow-up study of saffron supplementation in early age-related macular degeneration: Sustained benefits to central retinal function. Evid. Based Complementary Alternat. Med. 2012, 2012, 429124. [CrossRef] [PubMed]

22. Corso, L.; Cavallero, A.; Baroni, D.; Garbati, P.; Prestipino, G.; Bisti, S.; Nobile, M.; Picco, C. Safron reduces ATP-induced retinal cytotoxicity by Targeting P2X7 receptors. Purinergic Signal. 2016, 12, 161-174. [CrossRef] [PubMed]

23. Woo, J.M.; Shin, D.-Y.; Lee, S.J.; Joe, Y.; Zheng, M.; Yim, J.H.; Callaway, Z.; Chung, H.T. Curcumin protects retinal pigment epithelial cells against oxidative stress via induction of heme oxygenase-1 expression and reduction of reactive oxygen. Mol. Vis. 2012, 18, 901-908. [PubMed]

24. Silván, J.M.; Reguero, M.; de Pascual-Teresa, S. A protective effect of anthocyanins and xanthophylls on UVB-induced damage in retinal pigment epithelial cells. Food Funct. 2016, 7, 1067-1076. [CrossRef] [PubMed] 
25. Nguyen-Ngo, C.; Willcox, J.C.; Lappas, M. Anti-inflammatory effects of phenolic acids punicalagin and curcumin in human placenta and adipose tissue. Placenta 2020, 100,1-12. [CrossRef] [PubMed]

26. Viladomiu, M.; Hontecillas, R.; Lu, P.; Bassaganya-Riera, J. Preventive and prophylactic mechanisms of action of pomegranate bioactive constituents. Evid. Based Complementary Altern. Med. 2013, 2013, 789764. [CrossRef] [PubMed]

27. Seeram, N.P.; Adams, L.S.; Henning, S.M.; Niu, Y.; Zhang, Y.; Nair, M.G.; Heber, D. In vitro antiproliferative, apoptotic and antioxidant activities of punicalagin, ellagic acid and a total pomegranate tannin extract are enhanced in combination with other polyphenols as found in pomegranate juice. J. Nutr. Biochem. 2005, 16, 360-367. [CrossRef]

28. Lin, C.C.; Hsu, Y.F.; Lin, T.C.; Hsu, H.Y. Antioxidant and hepatoprotective effects of punicalagin and punicalin on acetaminopheninduced liver damage in rats. Phytother. Res. 2001, 15, 206-212. [CrossRef]

29. Zahin, M.; Ahmad, I.; Gupta, R.C.; Aqil, F. Punicalagin and Ellagic Acid Demonstrate Antimutagenic Activity and Inhibition of Benzo[a]pyrene Induced DNA Adducts. BioMed Res. Int. 2014, 2014, 1-10. [CrossRef]

30. Cao, K.; Xu, J.; Pu, W.; Dong, Z.; Sun, L.; Zang, W.; Gao, F.; Zhang, Y.; Feng, Z.; Liu, J. Punicalagin, an active component in pomegranate, ameliorates cardiac mitochondrial impairment in obese rats via AMPK activation. Sci. Rep. 2015, 5, 14014. [CrossRef]

31. Berköz, M.; Krośniak, M. Punicalagin induces apoptosis in A549 cell line through mitochondria-mediated pathway. Gen. Physiol. Biophys. 2020, 39, 557-567. [CrossRef] [PubMed]

32. Zou, X.; Yan, C.; Shi, Y.; Cao, K.; Xu, J.; Wang, X.; Chen, C.; Luo, C.; Li, Y.; Gao, J.; et al. Mitochondrial Dysfunction in ObesityAssociated Nonalcoholic Fatty Liver Disease: The Protective Effects of Pomegranate with Its Active Component Punicalagin. Antioxid. Redox Signal. 2014, 21, 1557-1570. [CrossRef] [PubMed]

33. Clementi, M.E.; Sampaolese, B.; Sciandra, F.; Tringali, G. Punicalagin Protects Human Retinal Pigment Epithelium Cells from Ultraviolet Radiation-Induced Oxidative Damage by Activating Nrf2/HO-1 Signaling Pathway and Reducing Apoptosis. Antioxidants 2020, 9, 473. [CrossRef] [PubMed]

34. Clementi, M.E.; Pani, G.; Sampaolese, B.; Tringali, G. Punicalagin reduces $\mathrm{H}_{2} \mathrm{O}_{2}$-induced cytotoxicity and apoptosis in PC12 cells by modulating the levels of reactive oxygen species. Nutr. Neurosci. 2018, 21, 447-454. [CrossRef] [PubMed]

35. Clementi, M.E.; Lazzarino, G.; Sampaolese, B.; Brancato, A.; Tringali, G. DHA protects PC12 cells against oxidative stress and apoptotic signals through the activation of the NFE2L2/HO-1 axis. Int. J. Mol. Med. 2019, 43, 2523-2531. [CrossRef] [PubMed]

36. Bianchetti, G.; di Giacinto, F.; de Spirito, M.; Maulucci, G. Machine-learning assisted confocal imaging of intracellular sites of triglycerides and cholesteryl esters formation and storage. Anal. Chim. Acta 2020, 1121, 57-66. [CrossRef]

37. Bianchetti, G.; Viti, L.; Scupola, A.; di Leo, M.; Tartaglione, L.; Flex, A.; de Spirito, M.; Pitocco, D.; Maulucci, G. Erythrocyte membrane fluidity as a marker of diabetic retinopathy in type 1 diabetes mellitus. Eur. J. Clin. Investig. 2020, e13455. [CrossRef]

38. Bianchetti, G.; di Giacinto, F.; Pitocco, D.; Rizzi, A.; Rizzo, G.E.; de Leva, F.; Flex, A.; di Stasio, E.; Ciasca, G.; de Spirito, M.; et al. Red blood cells membrane micropolarity as a novel diagnostic indicator of type 1 and type 2 diabetes. Anal. Chim. Acta X 2019, 3 , 100030. [CrossRef]

39. Smiley, S.T.; Reers, M.; Mottola-Hartshorn, C.; Lin, M.; Chen, A.; Smith, T.W.; Steele, G.D., Jr.; Chen, L.B. Intracellular heterogeneity in mitochondrial membrane potentials revealed by a J-aggregate-forming lipophilic cation JC-1. Proc. Natl. Acad. Sci. USA 1991, 88, 3671-3675. [CrossRef]

40. Nobile, V.; Palumbo, F.; Lanni, S.; Ghisio, V.; Vitali, A.; Castagnola, M.; Marzano, V.; Maulucci, G.; de Angelis, C.; de Spirito, M.; et al. Altered mitochondrial function in cells carrying a premutation or unmethylated full mutation of the FMR1 gene. Hum. Genet. 2020, 139, 227-245. [CrossRef]

41. Dinkova-Kostova, A.T.; Abramov, A.Y. The emerging role of Nrf2 in mitochondrial function. Free. Radic. Biol. Med. 2015, 88, 179-188. [CrossRef] [PubMed]

42. Holmström, K.M.; Kostov, R.V.; Dinkova-Kostova, A.T. The multifaceted role of Nrf2 in mitochondrial function. Curr. Opin. Toxicol. 2016, 1, 80-91. [CrossRef] [PubMed]

43. Domènech, E.B.; Marfany, G. The Relevance of Oxidative Stress in the Pathogenesis and Therapy of Retinal Dystrophies. Antioxidants 2020, 9, 347. [CrossRef] [PubMed]

44. Marchi, S.; Giorgi, C.; Suski, J.M.; Agnoletto, C.; Bononi, A.; Bonora, M.; de Marchi, E.; Missiroli, S.; Patergnani, S.; Poletti, F.; et al. Mitochondria-Ros Crosstalk in the Control of Cell Death and Aging. J. Signal Transduct. 2012, 2012, 1-17. [CrossRef]

45. Georgieva, E.; Ivanova, D.; Zhelev, Z.; Bakalova, R.; Gulubova, M.; Aoki, I. Mitochondrial Dysfunction and Redox Imbalance as a Diagnostic Marker of "Free Radical Diseases". Anticancer Res. 2017, 37, 5373-5381. [CrossRef]

46. Plafker, S.M.; O’Mealey, G.B.; Szweda, L.I. Mechanisms for countering oxidative stress and damage in retinal pigment epithelium. Int. Rev. Cell Mol. Biol. 2012, 298, 135-177.

47. Bungau, S.; Abdel-Daim, M.M.; Tit, D.M.; Ghanem, E.; Sato, S.; Maruyama-Inoue, M.; Yamane, S.; Kadonosono, K. Health Benefits of Polyphenols and Carotenoids in Age-Related Eye Diseases. Oxidative Med. Cell. Longev. 2019, 2019, 9783429. [CrossRef]

48. Martínez-Solís, I.; Bosch-Morell, F.; Villagrasa, V.; Ortega, T.; Acero, N.; Muñoz-Mingarro, D.; González-Rosende, M.E.; Castillo, E.; Sanahuja, M.A.; Soriano, P. Medicinal plants and natural products as neuroprotective agents in age-related macular degeneration. Neural Regen. Res. 2020, 15, 2207-2216. [CrossRef]

49. Kulkarni, A.P.; Mahal, H.S.; Kapoor, S.; Aradhya, S.M. In Vitro Studies on the Binding, Antioxidant, and Cytotoxic Actions of Punicalagin. J. Agric. Food Chem. 2007, 55, 1491-1500. [CrossRef] 
50. Du, L.; Chen, J.; Xing, Y.-Q. Eupatilin prevents $\mathrm{H}_{2} \mathrm{O}_{2}$-induced oxidative stress and apoptosis in human retinal pigment epithelial cells. Biomed. Pharmacother. 2017, 85, 136-140. [CrossRef]

51. Zhao, H.; Wang, R.; Ye, M.; Zhang, L. Genipin protects against $\mathrm{H}_{2} \mathrm{O}_{2}$-induced oxidative damage in retinal pigment epithelial cells by promoting Nrf2 signaling. Int. J. Mol. Med. 2019, 43, 936-944. [CrossRef] [PubMed]

52. Nulton-Persson, A.C.; Szweda, L.I. Modulation of Mitochondrial Function by Hydrogen Peroxide. J. Biol. Chem. 2001, 276, 23357-23361. [CrossRef] [PubMed]

53. Kamel, K.; Farrell, M.; O’Brien, C. Mitochondrial dysfunction in ocular disease: Focus on glaucoma. Mitochondrion 2017, 35, 44-53. [CrossRef] [PubMed]

54. Wallace, D.C. Bioenergetic origins of complexity and disease. In Cold Spring Harbor Symposia on Quantitative Biology; Cold Spring Harbor Laboratory Press: Cold Spring Harbor, NY, USA, 2011; Volume 76, pp. 1-16.

55. Vanova, K.H.; Kraus, M.; Neuzil, J.; Rohlena, J. Mitochondrial complex II and reactive oxygen species in disease and therapy. Redox Rep. 2020, 25, 26-32. [CrossRef] [PubMed]

56. Sousa, J.S.; D'Imprima, E.; Vonck, J. Mitochondrial Respiratory Chain Complexes. Subcell Biochem. 2018, 87, 167-227.

57. Redza-Dutordoir, M.; Averill-Bates, D.A. Activation of apoptosis signaling pathways by reactive oxygen species. Biochim. Biophys. Acta (BBA) Mol. Cell Res. 2016, 1863, 2977-2992.

58. Ricci, J.E.; Gottlieb, R.A.; Green, D.R. Caspase-mediated loss of mitochondrial function and generation of reactive oxygen species during apoptosis. J. Cell Biol. 2003, 160, 65-75. [CrossRef]

59. Kang, B.; Kim, C.Y.; Hwang, J.; Jo, K.; Kim, S.; Suh, H.J.; Choi, H.S. Punicalagin, a Pomegranate-Derived Ellagitannin, Suppresses Obesity and Obesity-Induced Inflammatory Responses via the Nrf2/Keap1 Signaling Pathway. Mol. Nutr. Food Res. 2019, 63, e1900574. [CrossRef]

60. Xu, L.; He, S.; Yin, P.; Li, D.; Mei, C.; Yu, X.; Shi, Y.; Jiang, L.; Liu, F. Punicalagin Nrf2 translocation induces and HO-1 expression via PI3K/Akt, protecting rat intestinal epithelial cells from oxidative stress. Int. J. Hyperth. 2016, 32, 465-473. [CrossRef]

61. Suzuki, T.; Muramatsu, A.; Saito, R.; Iso, T.; Shibata, T.; Kuwata, K.; Kawaguchi, S.I.; Iwawaki, T.; Adachi, S.; Suda, H.; et al. Molecular mechanism of cellular oxidative stress sensing by Keap1. Cell Rep. 2019, 28, 746-758.

62. Cai, H.; del Priore, L.V. Gene expression profile of cultured adult compared to immortalized human RPE. Mol. Vis. 2006, $12,14$.

63. Ablonczy, Z.; Dahrouj, M.; Tang, P.H.; Liu, Y.; Sambamurti, K.; Marmorstein, A.D.; Crosson, C.E. Human retinal pigment epithelium cells as functional models for the RPE in vivo. Investig. Ophthalmol. Vis. Sci. 2011, 52, 8614-8620. [CrossRef]

64. Kokkinaki, M.; Sahibzada, N.; Golestaneh, N. Human iPS-derived retinal pigment epithelium (RPE) cells exhibit ion transport, membrane potential, polarized VEGF secretion and gene expression pattern similar to native RPE. Stem Cells 2011, 29, 825-835. [CrossRef] [PubMed]

65. Mannermaa, E.; Reinisalo, M.; Ranta, V.; Vellonen, K.-S.; Kokki, H.; Saarikko, A.; Kaarniranta, K.; Urtti, A. Filter-cultured ARPE-19 cells as outer blood-retinal barrier model. Eur. J. Pharm. Sci. 2010, 40, 289-296. [CrossRef] [PubMed] 